\title{
Synergistic effect on inhibiton efficiency of coconut husk fibre essence in controlling corrosion of mild steel in neutral medium
}

\author{
A. Sankar ${ }^{1 *}$, S. Ananth Kumar ${ }^{1}$ and S. Rameshkumar ${ }^{2}$ \\ ${ }^{1}$ Kandaswami Kandar's College, P. Velur, Namakkal-638 182, Tamil Nadu, India. \\ ${ }^{2}$ PSG College of Technology Peelamedu, Coimbatore 641 004, Tamil Nadu, India.
}

\begin{abstract}
The corrosion inhibition nature of coconut husk essence for the corrosion of mild steel in tank water (neutral medium) was investigated using weight loss, electrochemical impedance and Potentiodynamic Polarization methods. The results revealed that coconut husk essence acts as a corrosion inhibitor in well water. The inhibition efficiency increased with an increase in inhibitor concentration. The inhibition is attributed to adsorption of the inhibitor on the steel surface.
\end{abstract}

Keywords: Inhibitor; Weight loss; Impedance; Polarization; Coconut husk

\section{Introduction}

Corrosion inhibitors are widely used in industry to reduce the corrosion rate of metals and alloys in contact with aggressive environments. Most of the corrosion inhibitors are synthetic chemicals, expensive, and very hazardous to environments. Therefore, it is desirable to find an ecofriendly inhibitor. There are some reports on the inhibition effects of non-toxic compounds on the corrosion of metals Abd et al., (1999), Quraishi et al., (2001), Rajappa and Venkatesha (2002), Quraishi et al., (2003). We have recently reported the inhibition effect of amino acids on the steel and aluminum corrosion in acidic media. The rare earth metals have been proposed as corrosion inhibitors. The inhibition effects of some non-toxic organic compounds have been also reported for steel corrosion but they are expensive Ahamad et al., (2010), Kertit and Hamouti (1996), Quraishi and Rawat (2002), Bilgie et al., (2003), Awad (1985).. The aim of the study was to investigate the inhibition effect of coconut husk essence as a cheap, raw and non-toxic corrosion inhibitor on mild steel corrosion in neutral medium. The electrochemical measurements were also used to evaluate the inhibition efficiencies.

The Objective of the present work is as follow:

1) To evaluate the inhibition efficiency (IE) of an aqueous extract of coconut husk $(\mathrm{CH})$ in controlling the corrosion of mild steel in well water, in the absence and presence of $\mathrm{Zn}^{2+}$ ions.
2) To understand the mechanic aspects of corrosion inhibition by Potentiodynamic polarization studies and $\mathrm{AC}$ impendence methods; and

3) To propose a suitable mechanism for corrosion inhibition.

\section{Experimental part}

Preparation of extrac

An aqueous extract of coconut husk was prepared by soaking $20 \mathrm{~g}$ of coconut husk with well water in one week, filtering the suspending impurities and making up to $100 \mathrm{ml}$. The extract was used as stock solution.

\section{Preparation of specimens}

Carbon steel specimens $(0.022 \% \mathrm{~S}, 0.038 \% \mathrm{Mn}, 0.027 \% \mathrm{P}$, $0.086 \mathrm{C}$ ) of dimension $1.0 \mathrm{~cm} \mathrm{x} 4.0 \mathrm{~cm} \times 0.2 \mathrm{~cm}$ were polished to a mirror finished with the emery sheets of various grades and degreased with trichloroethylene.

\section{Weight loss method}

Relevant data on the well water used in the study are given in table 1. Carbon steel specimens in triplicate were immersed in $100 \mathrm{ml}$ of the solutions containing various concentrations of the inhibitor in the presence and absence of $\mathrm{Zn}^{2+}$ for one day. The weight of the specimens before and after immersion was determined using Shimadzu balance, model Ay 62. The inhibition efficiency (IE) was then calculated using the equation.

*Corresponding author: sanvishnu2010@gmail.com 


$$
\mathrm{IE} \%=\left(\frac{\mathrm{W}_{1}-\underline{W}_{2}}{\mathrm{~W}_{1}}\right) \times 100
$$

Where $\mathrm{W}_{1}$ and $\mathrm{W}_{2}$ are the corrosion rates in the absence and presence of the inhibitor respectively.

Table I. Parameters of well water

\begin{tabular}{ll}
\hline Parameter & Value \\
\hline $\mathrm{pH}$ & 7.90 \\
Conductivity & $3100 \mu \mathrm{mhos} / \mathrm{cm}$ \\
TDS & $2008 \mathrm{ppm}$ \\
Chloride & $610 \mathrm{ppm}$ \\
Sulphate & $11 \mathrm{ppm}$ \\
Total hardness & $1075 \mathrm{ppm}$ \\
\hline
\end{tabular}

Impedance measurements

The electrochemical impedance measurements were carried out using a Potentiostat/Galvanostat/FRA (PARSTAT 2273, Princeton Applied Research, USA). Data acquisition was performed utilizing the PowerSuite software and analyzed using Zsimp Win software (version 3.21). A three electrode set up was employed with Pt foil as the auxiliary electrode and a saturated calomel electrode as the reference electrode. The mild steel cylinder, with surface prepared as described in the weight loss experimental method, served as the working electrode. The measurements were carried out in the frequency range $10^{6}-10^{-2} \mathrm{~Hz}$ at the open circuit potential by superimposing a sinusoidal AC signal of small amplitude, 10 $\mathrm{mV}$, after immersion for $30 \mathrm{~min}$ in the corrosive media. The double layer capacitance $\left(\mathrm{C}_{\mathrm{d} 1}\right)$ and charge transfer resistance $\left(\mathrm{R}_{\mathrm{ct}}\right)$ were obtained from the impedance plots as described elsewhere (Ananth et al., 2013). Because $\mathrm{R}_{\mathrm{ct}}$ is inversely proportional to corrosion current density, it was used to determine the inhibition efficiency (IE \%) using the relationship:

$$
\mathrm{IE} \%=\frac{\mathrm{Rct}-\mathrm{R}^{\circ} \mathrm{ct}}{\mathrm{Rct}} \times 100
$$

where $\mathrm{R}_{\mathrm{ct}}$ and $\mathrm{R}_{\mathrm{ct}}^{0}$ are the charge transfer resistance values in the uninhibited and inhibited solutions respectively.

\section{Polarization measurements}

The Potentiodynamic polarization curves were recorded using the same cell setup employed for the impedance measurements. The potentials were swept at the rate of $1.66 \mathrm{mVs}^{-1}$, primarily from a more negative potential than $\mathrm{E}_{\text {ocp }}$ to a more positive potential than $\mathrm{E}_{\text {ocp }}$ through $\mathrm{E}_{\text {corr }}$. The inhibition efficiencies were calculated using the relationship (Baorong et al., 2008).

$$
\mathrm{IE} \%=\frac{\mathrm{I}^{\circ} \mathrm{corr}-\mathrm{Icorr}}{\mathrm{I}^{\circ} \mathrm{corr}} \times 100
$$

where $\mathrm{I}_{\text {corr }}^{0}$ and $\mathrm{I}_{\text {corr }}$ are the corrosion current densities in the absence and in the presence of inhibitor respectively.

\section{Results and discussion}

\section{Analysis of result of weight loss method}

The corrosion rates (CR) of carbon steel immersed in well water in the absence and presence of inhibitor system are given table 2. The inhibition efficiencies (IE) are also given in this table. It is seen from table 2 that the $2 \% \mathrm{v} / \mathrm{v}$ aqueous extract of coconut husk $(\mathrm{CH})$ shows $58 \%$ inhibition efficiency for the corrosion of carbon steel in well water and it increases with increase in volume of stock solution added to the corrosive media.

Table II. Corrosion rate (CR) of carbon steel in well water in the absence and presence of inhibitors, and the inhibition efficiency (IE) obtained by weight loss method.

\section{Immersion period: one day}

Inhibitor: 10\%Aqueous extract of Coconut husk (CH)- $\mathrm{Zn}^{2+}$.

\begin{tabular}{|c|c|c|c|c|}
\hline \multirow{2}{*}{$\begin{array}{c}\text { Inhibitor } \\
\text { Concentration } \\
\text { (v/v\%) }\end{array}$} & \multicolumn{2}{|c|}{$\mathbf{Z n}^{2+} \mathbf{( 0 )} \mathbf{~ p p m}$} & \multicolumn{2}{c|}{$\mathbf{Z n}^{2+}(\mathbf{5 0 )} \mathbf{~ p p m}$} \\
\cline { 2 - 5 } & $\begin{array}{c}\mathbf{C R} \\
\text { (mdd) }\end{array}$ & $\begin{array}{c}\text { IE } \\
\mathbf{( \% )}\end{array}$ & $\begin{array}{c}\mathbf{C R} \\
\text { (mdd) }\end{array}$ & $\begin{array}{c}\mathbf{I E} \\
\mathbf{( \% )}\end{array}$ \\
\hline 0 & 31.25 & 0 & 31.25 & 0 \\
2 & 13.13 & 58 & 5.63 & 82 \\
4 & 8.75 & 72 & 4.38 & 86 \\
6 & 8.12 & 74 & 3.13 & 90 \\
8 & 7.50 & 76 & 3.13 & 90 \\
\hline
\end{tabular}

Influence of $z n 2+$ on the inhibition efficiency of ch

The influence of $\mathrm{Zn}^{2+}$ on the IE of $\mathrm{CH}$ can also be seen from table 2. In the presence of $\mathrm{Zn}^{2+}$ (50ppm) the inhibitor shows excellent inhibition efficiency at all concentrations. This suggests that a synergistic effect exists between $\mathrm{CH}$ and $\mathrm{Zn}^{2+}$.

Influence of duration of immersion on the ch of (8ml)- $\left.z n^{2+} 50 \mathrm{ppm}\right)$

The Influence of duration of immersion on the $\mathrm{CH}$ of $(8 \mathrm{ml})$ $\mathrm{Zn}^{2+} 50 \mathrm{ppm}$ ) system is given in table 3. It is found that the formulation consisting of $\mathrm{CH}$ and $\mathrm{Zn}^{2+}$ shows good IE even up to 7 days. The protective film is formed. This prevents corrosion of metal. This formulation may find application in cooling water systems, provided the experiments are carried out at higher temperature and dynamic condition. 
Table III. Influence of duration of immersion on IE of (CH8ml)-Zn ${ }^{2+}$ 50ppm

\begin{tabular}{|l|r|r|r|c|}
\hline \multirow{2}{*}{$\begin{array}{l}\text { Inhibitor Concentration (v/v\%) } \\
\text { (CH8ml)-Zn' }\end{array} \mathbf{2}^{2} \mathbf{5 0 p p m}$} & \multicolumn{4}{|c|}{ Immersion Period (days) } \\
\cline { 2 - 5 } & $\mathbf{1}$ & $\mathbf{3}$ & $\mathbf{5}$ & $\mathbf{7}$ \\
\hline $\mathrm{IE}(\%)$ & 90 & 90 & 90 & 89 \\
\hline
\end{tabular}

The active principle for corrosion inhibition

Organic compounds containing electron donor atoms like Nitrogen, oxygen and sulphur have been found to be effective corrosion inhibitors for steel (Sarkanan and Ludwig 1971). The existing data showing that the inhibition action of most of the organic compounds is due to the adsorption of their molecules on their metal surface. The most favorable qualities possessed by compounds to act as efficient inhibitor. The active principle for corrosion inhibition is an aqueous extract of coconut husk fibre is lignin compound. This is polyphenolic compound, which is found in secondary cell walls. The structure of the Lignin compound is as follows Sarkanan and Ludwig (1971), Arthur et al., (1996).

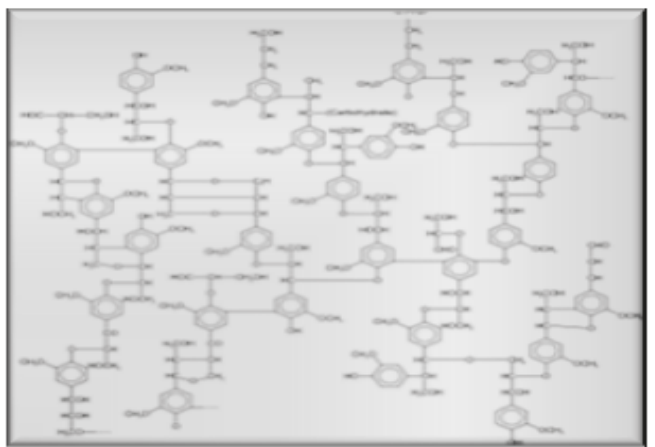

Fig.1. The structure of the Lignin compound

\section{Polarization studies}

Electrochemical parameters like corrosion potential $\left(\mathrm{E}_{\mathrm{corr}}\right)$, corrosion current density $\left(\mathrm{I}_{\text {corr }}\right)$, cathodic Tafel slope $\left(\mathrm{b}_{\mathrm{c}}\right)$, anodic Tafel slope $b_{a}$ and percentage inhibition efficiency according to polarization studies are listed in table 4 . Here $\mathrm{I}_{\text {corr }}$ decreased with increasing inhibitor concentration from $2 \%$ to $8 \% \mathrm{v} / \mathrm{v}$. It is clearly observed that the coconut husk fibre essence reduce the corrosion current density.

Table IV. Corrosion parameters in the presence and absence of inhibitor obtained from Polarization measurements.

\begin{tabular}{cccccr}
\hline $\begin{array}{c}\text { Inhibitor } \\
\text { Concentration } \\
(\mathbf{v} / \mathbf{v} \%)\end{array}$ & $\begin{array}{c}-\mathbf{E}_{\text {corr }} \\
(\mathbf{m V} \\
\mathbf{S C E})\end{array}$ & $\begin{array}{c}\mathbf{b}_{\mathbf{c}} \\
(\mathbf{m V d e c})\end{array}$ & $\begin{array}{c}\mathbf{b}_{\mathbf{a}} \\
\left(\mathbf{m V d e c} \mathbf{d}^{-1}\right)\end{array}$ & $\begin{array}{c}\mathbf{I}_{\text {corr }} \times \mathbf{1 0}^{6} \\
(\boldsymbol{\mu A})\end{array}$ & $\begin{array}{c}\mathbf{I E} \\
(\mathbf{\%})\end{array}$ \\
\hline 0 & 503 & 491 & 80 & 8.498 & --- \\
2 & 529 & 370 & 190 & 4.354 & 48.76 \\
4 & 550 & 484 & 150 & 3.117 & 63.32 \\
6 & 558 & 499 & 171 & 2.429 & 71.41 \\
8 & 582 & 653 & 185 & 1.895 & 77.77 \\
\hline
\end{tabular}

Corrosion current density decreased noticeably with increase in inhibitor concentration, indicating the increased inhibition efficiency with the increase in the concentration of the inhibitor. $\mathrm{E}_{\text {corr }}$ value shifted towards more negative potential. It has been reported that a compound can be classified as an anodic and cathodic type inhibitor on the basis of shift $\mathrm{E}_{\text {cor }}$ value. If displacement of $\mathrm{E}_{\text {corr }}$ value is greater than $85 \mathrm{mV}$ SCE, towards anode or cathode with reference to the blank, an inhibitor is categorized as either anodic or cathodic type inhibitor. Otherwise inhibitor is treated as mixed type.

In our study, maximum displacement in $\mathrm{E}_{\text {corr }}$ value was around around $79 \mathrm{mV} \mathrm{SCE}$, indicating inhibitor is a mixed type inhibitor with more cathodic nature. $b_{c}$ and $b_{a}$ values changed with respect to the inhibitor concentration. Therefore, coconut husk fibre essence could be classified as a mixed type inhibitor suggesting that the presence of the inhibitor does not alter the reaction mechanism, and that the inhibition effect has occurred due to simple blocking of the active sites, thereby reducing available surface area of the corroding metal.

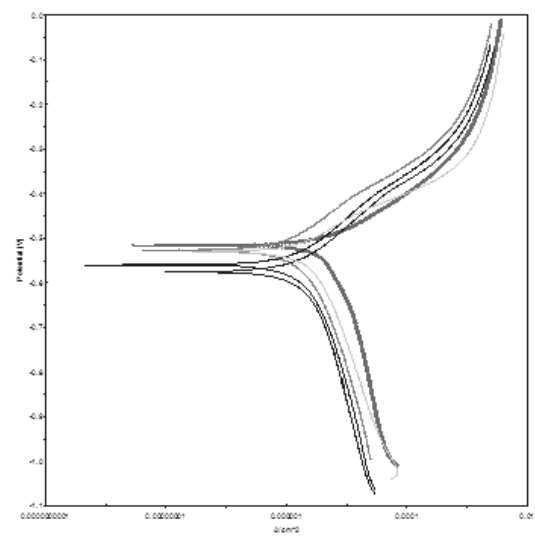

Fig. 2. Polarization curves of carbon steel immersed in well water in the various concentration of inhibitors.

\section{Electrochemical impedance spectroscopic measurements (eis)}

Impedance spectra obtained for corrosion of mild steel in well water contains two semicircles in which the second one represents the interaction of metal surface with the corrosive environment. The first semicircle represents the nature of the corrosive media. Since the conductivity of the corrosive medium is very low, this also behaves like a leaky capacitor. The CR-CR model best describes this situation. The second semicircle in the impedance plots contain depressed semicircles with the centre below the real axis. The size of the semicircle increases with the inhibitor concentration, indicating the charge transfer process as the main controlling factor of the corrosion of mild steel. It is apparent from the plots that the impedance of the inhibited solution has 
increased with the increase in the concentration of the inhibitor. The experimental results of EIS measurements for the corrosion of mild steel in tank water in the absence and presence of inhibitor are given in Table 5. (Papova et al., 1996). reported that sum of charge transfer resistance $\left(R_{c t}\right)$ and adsorption resistance $\left(\mathrm{R}_{\mathrm{ad}}\right)$ is equivalent to polarization resistance $\left(R_{p}\right)$.

Table V. Impedance parameters obtained from electrochemical impedance studies.

\begin{tabular}{|c|c|c|c|}
\hline $\begin{array}{c}\text { Inhibitor } \\
\text { Concentration } \\
(\mathbf{v} / \mathbf{v} \%)\end{array}$ & $\begin{array}{c}\text { Ret } \\
\left(\mathrm{Ohm} \mathbf{c m}^{2}\right)\end{array}$ & $\begin{array}{l}\mathrm{C}_{\mathrm{dl}} \\
(\mu \mathrm{F})\end{array}$ & $\begin{array}{l}\text { IE } \\
(\%)\end{array}$ \\
\hline 0 & 24030 & 10.55 & --- \\
\hline 2 & 54780 & 2.376 & 56.13 \\
\hline 4 & 59430 & 2.145 & 59.56 \\
\hline 6 & 75210 & 1.496 & 68.04 \\
\hline 8 & 97340 & 0.0200 & 75.31 \\
\hline
\end{tabular}

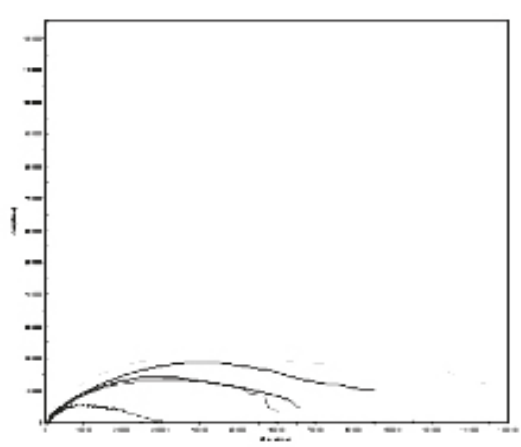

Fig 3. Electrochemical impedance spectroscopy of carbon steel immersed in well water in the various concentrations of inhibitors.

\section{Conclusion}

Results obtained from both electrochemical and gravimetric methods showed that the coconut husk fiber essence acts as an inhibitor for corrosion of steel in hydrochloric acid media. Corrosion inhibition action of coconut husk fibre essence increased as its concentration increases. Inhibition of steel in $\mathrm{HCl}$ solution by coconut husk fiber essence is attributed to adsorption of the Lignin compound in this.

\section{References}

Abd SS, El-Rehim, Khalid KF (1999), 4-Aminoantipyrine as an inhibitor of mild steel corrosion in $\mathrm{HCl}$ solution, $J$ Appl. Electrochem, 29: 593-599.

Ahamad Ishtiaque, Prasad Rajendra and Quraishi M.A (2010), Adsorption and inhibitive properties of some new Mannich bases of Isatin derivatives on corrosion of mild steel in acidic media, Corros. Sci., 52(4): 1472-1481.
Awad G.H (1985), Effect of sme plant Extracts on the corrosion of mild steel in $0.1 \mathrm{~N}$ Hydrochloric acid solution, Pro. $6^{\text {th }}$ Eurpean symp. On corrosion inhibitors, 1: 385 .

Ananth Kumar S, Ramesh Kumar S and Sankar A (2013), Corrosion Inhibition of Mild steel in Acid Media by Alpina galinga Extract, 4: 2278-5736.

Arthur J, Froass and Peter M (1996), Chemical Structure of residual lignin from Kraft pulp, Journal of Wood Chemistry and Technology, 1(4): 347-365.

Bilgie S, Shahin M and Yilmaz H (2003), The inhibition effects of some cyclic nitrogen Compounds on the corrosion of the steel in $\mathrm{NaCl}$ media, Appl.Surf.Sci.195: 1.

Baorong Hou, Lankun C, Weihua L and Ying Yan (2008), Electrochemical and quantum chemical study of purines as corrosion inhibitors for mild steel in $1 \mathrm{M} \mathrm{HCl}$ solution, Electrochim. Acta, 53(20): 5953-5960.

Kertit S and Hamouti. B (1996), 1-Phenyl-5-Mercapto-1,2,3,4-Tetrazole as corrosion inhibitor or iron in 1M HCl., App.Surf.Sci., 93: 59-66.

Popova A., Raicheva S., and Sokolova E (1996), Frequency Dispersion of the Interfacial Impedance at Mild Steel Corrosion in Acid Media in the Presence of Benzimidazole Derivatives, Langmuir, 12(8): 2083-2089.

Quraishi MA, Sardar R, Jamal (2001), Corrosion inhibition of mold steel in hydrochloric acid by some aromatic hydrzides, Mater. Chem. Phys., 71(3): 30 -313.

Quraishi MA, Danish Jamal, Dianils (2003), A new and effective corrosion inhibitors for mild steel in acidic solutions, Mater. Chem. Phys., 78(3): 608-613

Quraishi MA. And Rawat J (2002), Corrosion inhibiting action of tetramethyl-dithia-octaaza- Cyclotetradecahexaene on corrosion of mild steel in hot $20 \%$ sulfuric acid, Mater.Chem. Phys.73: 118.

Rajappa SK, Venkatesha TV (2002), New condensation products as corrosion inhibitors for mild steel in an hydrochloric acid medium, Indian J Eng. Mater Sci,.(9): $213-217$.

Sarkanan K.V and Ludwig C.H (1971), Occurrence, Formation, Structure and Reactions, Interscience: New York.916.

Received: 13 September 2013; Revised: 25 June 2014; Accepted: 25 August 2014. 